\title{
ANNOUNCEMENTS
}

\author{
ASTM Seeks Papers for October 1984 \\ Symposium on Functional Testing \\ for Hazard Evaluation
}

Papers are sought for a Symposium on Functional Testing for Hazard Evaluation to be held 30-31 October, 1984 in Fort Lauderdale, Florida. The symposium is sponsored by ASTM Committee D-19 on Water and is chaired by Dr. John Cairns of Virginia Polytechnic Institute and State University.

The purpose of this symposium is to determine what functional tests are available for pollution assessment. The attributes of a functional test should be the determination of how an aquatic population, community, or ecosystem is performing so that various key rate processes are assessed.

Papers concerning such functional tests are sought, including those on nutrient spiraling, energy transfer, rate of carbon fixation, rate of $\mathrm{CO}_{2}$ production, rate of phosphorus uptake, and any other rate process of ecological significance.

Prospective authors are requested to submit a title, three copies of a 300- to 500-word abstract, and an ASTM Paper Submittal Form by 15 January, 1984 to Kathy Greene, ASTM Acquisition \& Review, 1916 Race Street, Philadelphia, Pennsylvania 19103, 215/299-5414. Paper Submittal Forms can be obtained from Greene. Accepted abstracts may be printed and distributed at the symposium with the approval of the chairman.

For additional information on the Symposium on Functional Testing for Hazard Evolution, contact Dr. John Cairns, Virginia Polytechnic Institute and State University, Center for Environmental Studies, Biology Department, 1020 Derring Hall, Blacksburg, Virginia 24061, 703/961-5539; or Earl Sullivan, ASTM Standards Development Division, 1916 Race Street, Philadelphia, Pennsylvania 19103, 215/299-5514.

\section{2nd International Conference on}

\section{Fixed Film Biological Processes}

The 2nd International Conference on Fixed Film Biological Processes will be held July 10-12, 1984, at Hyatt Regency Hotel, Crystal City, Arlington, Virginia (Adjacent to Washington, D.C. National Airport). The Conference will be sponsored by the University of Pittsburgh in cooperation with the U.S. Environmental Protection Agency, the U.S. Army Construction Engineering Research Laboratory, the U.S. National Science Foundation, and the Japanese Soil Purification Center (Dojo Joka Senta). The fixed-film wastewater treatment systems include rotating biological contactors, biofiltration towers, moving, fixed, expanded, fluidized, and sludge bed reactors, and others. For more information contact Prof. Yeun C. Wu, 944 Benedum Hall, Department of Civil Engineering, University of Pittsburgh, Pittsburgh, PA 15261, U.S.A.; phone: (412) 624-5357 or 5358. 